\title{
The Relationship Between Long Non-Coding RNA Expressions and Ponatinib in Breast Cancer
}

\author{
Tuğçe Balcı Okcanoğlu' (D, Çağla Kayabașı² (D), Sunde Yılmaz Süslüer² (D), Cumhur Gündüz² (1) \\ 'Department of Medical Biology, Near East University, Vocational School of Health Services, Cyprus \\ 2Department of Medical Biology, Ege University School of Medicine, İzmir, Turkey
}

ORCID IDs of the authors: T.B.O. 0000-0003-06I3-765X; C..K. 0000-0002-6797-7655; S.Y.S. 0000-0002-0535-I50X; C.G. 0000-0002-6593-3237.

Cite this article as: Balcı Okcanoğlu T, Kayabașı T, Yılmaz Süslüer S, Gündüz C. The Relationship Between Long Non-Coding RNA

Expressions and Ponatinib in Breast Cancer. Cyprus J Med Sci 2019; 4(2): 125-30.

\section{BACKGROUND/AIMS}

Breast cancer is the most common type of cancer in women and is among the leading causes of cancer-related deaths. Long non-coding RNAs (IncRNAs) play significant roles in cell proliferation, transcriptional regulation, cell cycle progression, apoptosis, carcinogenesis, and metastasis. Studies have shown that ponatinib has an antiproliferative effect in some types of cancer. The aim of the present study was to evaluate the effect of ponatinib on cytotoxicity and to determine changes in IncRNA expression levels with the use of ponatinib treatment in estrogen receptor (ER)-independent MDA-MB-23I and ER-dependent MCF-7 breast cancer cells.

\section{MATERIAL and METHODS}

The cytotoxic effects of ponatinib were determined by using the xCELLigence system. Changes in IncRNA expression profiles were determined using quantitative reverse transcription polymerase chain reaction to investigate the antiproliferative roles of ponatinib in breast cancer.

\section{RESULTS}

In human breast adenocarcinoma cell lines (MCF-7 and MDA-MB-23I), the IC50 doses of ponatinib were determined to be $4.59 \mu \mathrm{M}$ (72 $\mathrm{h}$ ) and I.4I $\mu \mathrm{M}(48 \mathrm{~h})$, respectively. After ponatinib treatment, we observed changes in IncRNA expression profiles in ER-independent MDAMB-23I and ER-dependent MCF-7 breast cancer cells compared with the control group.

\section{CONCLUSION}

The changes in the IncRNA expression profiles and the anti-cancer agent of ponatinib play roles in the definition of therapeutic target for new approach in breast cancer.

Keywords: Long non-coding RNAs (IncRNAs), ponatinib, MCF-7, MDA-MB-23I, breast cancer

\section{INTRODUCTION}

Breast cancer is common in women and is characterized by high rates of malignancy and metastasis (I). Since breast cancer has a heterogeneous molecular structure, there is no common treatment strategy. Most patients develop resistance during treatment. Therefore, it has been found that alternative medicine sources are used as new options for breast cancer treatment (2).

Ponatinib, a strong tyrosine kinase inhibitor, targets BCR-ABLI oncoprotein. It has antiangiogenic and antineoplastic activities. It has been applied in the treatment of hematological malignancies, such as Philadelphia chromosome-positive acute lymphoblastic leukemia and chronic myeloid leukemia (3). In addition, the antineoplastic effects of ponatinib on various cancer cells, such as endometrial, bladder, stomach, breast, lung, and colon cancers, have been demonstrated (4). Ponatinib has been shown to induce dose-dependent G2/M arrest in ovarian and MCF-7 breast cancer cells, but does not block the cell cycle in colon and SKBR3 breast cancer cells (5).

Long non-coding RNA (IncRNA) is a kind of non-coding RNA (ncRNA) molecule longer than 200 nucleotides (6, 7). IncRNAs play biological roles in cell proliferation, proliferation, metabolic functions and differentiation, and the development of many diseases. They also play a role in genomic imprinting, gene regulation, alternative splicing, chromatin organization, and genomic packaging. The abnormal regulation of IncRNAs is associated with the formation, development, and progression of different 
types of diseases, particularly cancer. Specific IncRNAs are considered as indicators of diagnostic, prognostic, or predictive therapeutic responses for various diseases (8). Various studies have been conducted on IncRNAs. For example, it was shown that HOXAllAS inhibits the formation of cell colonies in the breast cancer cell line and arrests the cell cycle in the G0/Gl phase (9).

In conclusion, in our study, the antiproliferative effects of ponatinib and IncRNA expression profile were found in breast cancer. Some IncRNA genes have been shown to have anti-cancer effects. We believe that ponatinib can be used as a candidate biomarker for future effective treatment of breast cancer.

\section{MATERIAL and METHODS}

\section{Cell Culture}

MDA-MB-23I and MCF-7 cell lines were obtained from ATCC (Guernsey, Ireland). MCF-7 cells were cultured with RPMI-1640 (Biological Industries, Beit-Haemek, Israel), and MDA-MB-23I cells were cultured with Leibovitz's L-I5 (Biological Industries) media containing 1\% L-glutamine (EMD Millipore, K0282, Darmstadt, Germany), 10\% inactivated fetal bovine serum (Capricorn Scientific, FBS-IIB, Ebsdorfergrund, Germany), and I\% penicillin/ streptomycin (Biochrom, A2213, Berlin, Germany) in $5 \% \mathrm{CO}_{2}$ and $37^{\circ} \mathrm{C}$. Ponatinib (Selleckchem, Munich, Germany) was suspended in dimethyl sulfoxide (Sigma-Aldrich, Taufkirchen, Germany). Our study was conducted according to the Declaration of Helsinki.

\section{Cytotoxicity Assay}

MCF-7 and MDA-MB-23I ( $\mid \times 10^{4}$ cells/well) were seeded in 96well E-plates in triplicate to investigate the cytotoxic effects of ponatinib. The cells were incubated for $24 \mathrm{~h}$ before ponatinib treatment. MCF-7 cells were treated with ponatinib with concentrations of between $100 \mu \mathrm{M}$ and 3.I $\mu \mathrm{M}$, whereas MDAMB-23I cells were treated with ponatinib doses of $50 \mu \mathrm{M}-1.5$ $\mu \mathrm{M}$. The cells were incubated for $48 \mathrm{~h}$, and impedance was monitored every 15 min throughout the period using the $\mathrm{xCEL}$ Ligence system. Cytotoxicity was evaluated by comparing the viabilities of the ponatinib-treated cells to the untreated control cells using the $x$ CELLigence RTCA software.

\section{MCF-7 Ponotinib}

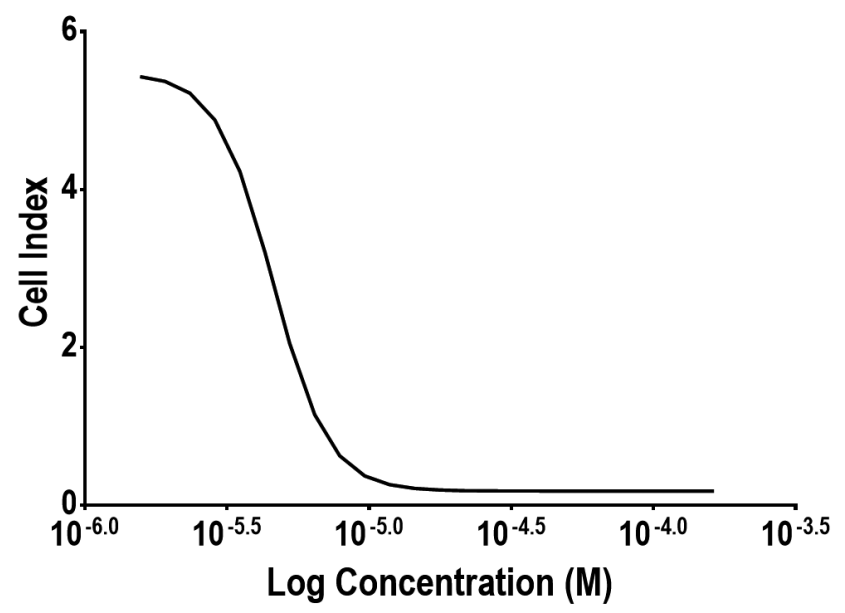

FIGURE I. Cyłotoxic effect of ponatinib in MCF-7 cell line

\section{IncRNA Expression Profiling}

\section{Total RNA isolation and cDNA synthesis}

For IncRNA expression profiling studies, RNeasy Mini Kit (Qiagen, Kat. No: 74134) was used to extract total RNA (including small RNAs) from the ponatinib-treated and -untreated MDAMB-23I and MCF-7 cells $\left(2 \times 10^{6}\right.$ cells $\left./ \mathrm{mL}\right)$. The concentration and purity of RNA samples were determined by measuring absorbance at wavelengths of 260/280 $\mathrm{nm}$ and $230 / 260 \mathrm{~nm}$ using the NanoDrop instrument (Thermo Scientific, Wilmington, DE, USA). For further analysis, RNA samples with A260/A280 and A230/ A260 absorbance ratios $>2.0$ were used.

\section{qRT-PCR analysis}

For cDNA synthesis, an RNAQuant cDNA Synthesis Kit (System Biosciences, CA, USA) was used according to the manufacturer's instruction. The Disease-Related IncProfiler Array was used to investigate the antiproliferative roles of IncRNAs in breast cancer after ponatinib treatment. Relative quantitation of 83 IncRNAs was measured by using a Maxima SYBR Green qPCR Master Mix (Thermo Scientific) on LightCycler 480 II (Roche Life Science, Indianapolis, IN, USA). In addition to seven human housekeeping genes (ACTB, B2M, PGKI, GAPDH, HPRTI, RPLIA, and RPLI3A) and four small RNA transcript primers (7SL sCRNA, 5.8S rRNA, U87 scaRNAU6, and smRNA) for normalization, the quantitative reverse transcription polymerase chain reaction (qRT-PCR) array plate included one genomic DNA control and one negative control. The relative expression of IncRNAs was determined by using the $2^{-\triangle \Delta C T}$ method. Fold changes of IncRNA expression levels after ponatinib treatment were evaluated by comparing with the untreated control groups. Log2 transformation was applied to the $2^{-\Delta \Delta C+}$ values of the IncRNA expression in the control and ponatinib-treated groups. Fold changes for IncRNA expressions and their significance were calculated by Student's t-test using an online software (https://www.qiagen.com/ip/shop/genes-and-pathways/data-analysis-center-overview-page/) (GeneGlobe Data Analysis Center; Qiagen, Valencia, USA). Changes in IncRNA expression of \pm 2 -fold were compared with the control group. A $p$ value $<0.05$ was considered significant.

\section{MDA-MB-231 Ponotinib}

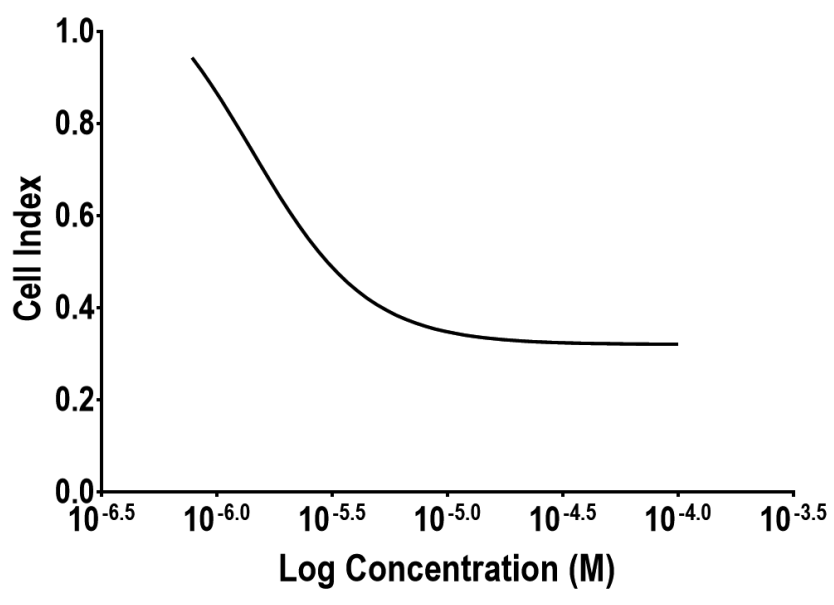

FIGURE 2. Cyłotoxic effect of ponatinib in MDA-MB-23I cell line 


\section{RESULTS}

\section{Cytotoxic Effect of Ponatinib}

MDA-MB-23I and MCF-7 cell lines revealed the cytotoxic effect of ponatinib by MTT analysis. The $\mathrm{IC}_{50}$ doses of ponatinib were determined to be $1.41 \mu \mathrm{M}$ for MDA-MB-23l cell line (48 h) and $4.59 \mu \mathrm{M}$ for MCF-7 cell line (72 h) at $48 \mathrm{~h}$ by using the $\times$ CELLigence system (Figure I, 2). Ponatinib inhibited cell proliferation in a dose- and time-dependent manner compared with the untreated MDA-MB-23I and MCF-7 control cells.

\section{Expression Profile Changes of IncRNA}

Following ponatinib treatment, changes in IncRNA expression were found in MCF-7 and MDA-MB-23I cells compared with the control groups. According to log2 transformation, 17 IncRNAs (AAAI, aHIF, BC200, DISC2, EGO, HOXAIIAS, MALATI, MEG3, NEATI, NCRMS, PCAT-I, PCAT-I4, PCAT-43, SAF, SRA, WTI$A S$, and ZEB2NAT) were downregulated, whereas 5 IncRNAs (CMPD, DGCR5, HI9-AS, HARIA, and LIT) were upregulated in MCF-7 cell lines $(p<0.05)$ (Table I).

\begin{tabular}{|c|c|c|}
\hline IncRNA Symbols & Fold Change (Log2Transformed) & $\mathbf{p}$ \\
\hline AAAl & -11.7 & 0.000124 \\
\hline aHIF & -4.79 & 0.000056 \\
\hline BC200 & -2.13 & 0.000081 \\
\hline CMPD & 2.44 & 0.00029 \\
\hline DGCR5 & 2.02 & 0.000234 \\
\hline DISC2 & -3.6 & 0.000097 \\
\hline EGO & -2.79 & 0.00005 \\
\hline HI9-AS & 2.29 & 0.000842 \\
\hline HARIA & 5.38 & 0.000072 \\
\hline HOXAIIAS & -6.05 & 0.000086 \\
\hline LIT & 2.04 & 0.000616 \\
\hline MALATI & -2.69 & 0.000043 \\
\hline MEG3 & -3.68 & 0.000144 \\
\hline NEATI & -2.85 & 0.000019 \\
\hline NCRMS & -3.06 & 0.000063 \\
\hline PCAT-I & -5.29 & 0.000045 \\
\hline PCAT-14 & -5.02 & 0.000157 \\
\hline PCAT-43 & -2.20 & 0.000114 \\
\hline SAF & -2.37 & 0.000106 \\
\hline SRA & -2.97 & 0.000069 \\
\hline WTI-AS & -7.86 & 0.000072 \\
\hline WTI-AS & -2.54 & 0.000432 \\
\hline \multicolumn{3}{|c|}{$\begin{array}{l}\text { IncRNAs: Long non-coding RNA; aHIF: Hypoxia Inducible Factor; CMPD: } \\
\text { Cancer mutant proteom Database; DGCR5: DiGeorge Syndrome Critical } \\
\text { Region Gene 5; DISC2: Disrupted in schizophrenia 2; EGO: Eosinophil } \\
\text { Granule Ontogenesis; LIT: Late inhibitor of T4; MALATI: Metastasis As- } \\
\text { sociated Lung Adenocarcinoma Transcript I; NCRMS: Non-coding RNA } \\
\text { in Rhabdomyosarcoma; SAF: Serum Amyloid A- Activating Factor; SRA: } \\
\text { Steroid Receptor Activator }\end{array}$} \\
\hline
\end{tabular}

In addition, according to log2 transformation, 22 IncRNAs (AAAl, aHIF, BC200, BCMS, DLG2AS, GAS5, HI9, HOXAIIAS, IPW, LIPAI6, LIT, MALATI, MERIIC, NEATI, PCAT-I4, PCGEMI, RMRP, SOX2OT, TELOMERASE RNA, TMEVPGI, TUGI, UCAI) were downregulated, whereas 6 IncRNAs (IGF2AS, MEG3, PCAT-43, ST7OT2, ST7OT3, and WTI-AS) were upregulated in MDA-MB-23I cell lines $(p<0.05)$ (Table 2).

\section{DISCUSSION}

In recent years, ncRNAs have been extensively studied in various biological processes and in human diseases, including cancer (I0). Currently, a large number of human IncRNAs can act as biomarkers for cancer diagnosis and prognosis (II). Most of the IncRNAs are abnormally expressed in breast cancer; they act as tumor suppressors and oncogenes according to their function and expression patterns (12).

TABLE 2. Exchange of IncRNAs expression in ponatinib treated MDA-MB-23I cell line

\begin{tabular}{|c|c|c|}
\hline IncRNA Symbols & Fold Change (Log2Transformed) & $\mathbf{p}$ \\
\hline AAAI & -7.73 & 0.000312 \\
\hline aHIF & -2.66 & 0.000187 \\
\hline BC200 & -6.16 & 0.000031 \\
\hline BCMS & -4.80 & 0.000146 \\
\hline DLG2AS & -2.90 & 0.000132 \\
\hline GAS5 & -5.39 & 0.000082 \\
\hline HI9 & -5.15 & 0.000066 \\
\hline HOXAIIAS & -7.83 & 0.00012 \\
\hline IPW & -5.15 & 0.00006 \\
\hline IGF2AS & 2.93 & 0.00013 \\
\hline LIPAI6 & -2.44 & $0.000 \mid 47$ \\
\hline LIT & -2.99 & 0.000435 \\
\hline MALATI & -7.38 & 0.000015 \\
\hline MEG3 & 4.46 & 0.000065 \\
\hline MERIIC & -5.65 & 0.000055 \\
\hline NEATI & -4.17 & 0.000016 \\
\hline PCAT-14 & -2.93 & 0.000381 \\
\hline PCAT-43 & 3.54 & 0.00004 \\
\hline RMRP & -7.73 & 0.000007 \\
\hline SOX2OT & -5.28 & 0.000216 \\
\hline ST7OT2 & 3.33 & 0.000204 \\
\hline ST7OT3 & 2.67 & 0.000113 \\
\hline TELOMERASE RNA & -3.46 & 0.000539 \\
\hline TMEVPGI & -3.10 & 0.000714 \\
\hline TUGI & -3.48 & 0.000122 \\
\hline UCAI & -7.97 & 0.000073 \\
\hline WTI-AS & 2.91 & 0.000211 \\
\hline \multicolumn{3}{|c|}{$\begin{array}{l}\text { IncRNAs: Long non-coding RNA; aHIF: Hypoxia Inducible Factor; BCMS } \\
\text { Gene associated with multiple splicing B-cell neoplasia; IPW: Imprinted } \\
\text { Gene in Prader-Willi Sendrom; LIT: Late inhibitor of T4; MALATI: Metas- } \\
\text { tasis Associated Lung Adenocarcinoma Transcript I; MEG3: maternally } \\
\text { expressed } 3 \text { TMEVPGI: Theiler's mouse encephalomyelitis virus resume } \\
\text { candidate gene; ITUGI: Taurine RNA arranged upward I; UCAI: Associ- } \\
\text { ated with urethral cancer I }\end{array}$} \\
\hline
\end{tabular}


Long non-coding RNA HI9 is known to play an oncogenic role in breast cancer. Studies have shown that HI9 plays a critical role in cell survival and proliferation in estrogen receptor (ER)-positive breast cancer cells (I3). While silencing of HI9 in breast cancer cells reduces proliferation, overexpression of HI9 is suggested to accelerate cell cycle progression (14). Inhibition of $\mathrm{HI} 9$ reduces the metastasis of pancreatic cancer in vivo. Therefore, they showed that HI9 is a new candidate for treatment of pancreatic cancer (I5). In our study, ponatinib was suppressed in ER-negative breast cancer cells of HI9. We can associate the 5.15-fold reduction in HI9 expression with the tumorigenesis process.

Chen et al. (16) have shown that IGF2AS is involved as an epigenetic tumor suppressor in human prostate cancer. In our study on breast cancer, it was evaluated that the expression of IncRNA IGF2AS had a 2.93-fold increase, playing a role as a tumor suppressor.

Wang et al. (17) showed that overexpressed PCAT-I4 is associated with a poor prognosis in patients with hepatocellular carcinoma (HCC). PCAT-14 has been proposed as a new prognostic factor and therapeutic target because it regulates proliferation and cell cycle in HCC cells (17). Qiao et al. (18) showed that the downregulation of IncRNA PCAT-I inhibits proliferation, blocks cell cycle passage, and suppresses cyclin and c-myc expression in colorectal cancer cells. In our study, the expression of IncRNA PCAT-I4 and PCAT-I decreased with the effect of ponatinib. This may suggest that they induce apoptosis.

In their study on breast cancer, Iranpour et al. found that SOX2OT overexpresses tumor tissues compared with non-cancerous tissues. It has been observed that SOX2OT acts as oncogenesis, and that its expression is more negative for patients (19).

Farhangian et al. (20) found that SOX2OT expression shows a significant reduction compared with non-tumor tissues in gastric cancer (GC) samples. They showed that SOX2OT plays a tumor suppressor role with the downregulation of SOX2 in GC. It can also be a good biomarker in the diagnosis of the disease (20). In our study, at the expression level of SOX2OT, a 5.25-fold decrease was found in ER-negative breast cancer cells. The decrease in the expression level of SOX2OT in ponatinib-treated breast cancer cells reveals the antiproliferative effect of ponatinib. We think that studies on this subject can be used as a biomarker in the diagnosis and treatment of the disease.

In the present study, it was observed that the expression of BC200 increased in breast cancer. Among breast cancer tissues, it was observed that BC200 was expressed at a higher level in ER-positive tumors than in ER-negative tumors. BC200 has been shown to play a role as an oncogene in breast cancer. Therefore, BC200 can be shown as a prognostic marker and target to minimize irregular cell proliferation in ER-dependent breast cancer (2I). In their study with carboplatin, Wu et al. (22) found that the expression of BC200 increases in ovarian cancer cell lines. It was observed that the cells decreased their sensitivity to the drug by inhibiting BC200 (22). We found that this IncRNA BC200, which is defined as an oncogene in breast cancer, is suppressed with ponatinib in hormone-sensitive and -independent breast cancer cells.
CMPDI showed an antiproliferative effect in GC cell lines MKN-45 and SGC790I. In addition, CMPDI induced time- and dose-dependent apoptosis in MKN-45 cell lines (23). In our study, we showed that ponatinib-treated MCF-7 cells regulated the expression of the tumor suppressor IncRNA CMPDI. As with GC, CMPDI may also contribute to the antiproliferative effect of ponatinib in breast cancer cells.

Fung et al. (24) found that DGCR5 expression is significantly lower in bladder cancer tissues than in healthy tissues. The increased expression of DGCR5 showed a high survival rate. In addition, it was found that the overexpression of DGCR5 inhibited proliferation, colony formation, and cell cycle progression (24). According to these data, after ponatinib treatment, the expression of DGCR5 is increased in ER-positive breast cancer cells. We investigated that ponatinib may suppress metastasis and induce apoptosis in tumorigenesis progression.

It has been observed that the decreased expression of PVTI and the increased expression of HARIA in patients with diffuse glioma increased the survival rate of patients receiving chemotherapy and radiotherapy. PVTI and HARIA can be used as biomarkers in the diagnosis and treatment of diffuse gliomas (25). In our study, we observed that the expression level of HARIA was increased in ER-dependent breast cancer cell lines. As a result, ponatinib may have an apoptotic effect on MCF-7 cell lines in cytotoxic and tumorigenesis.

TUGI was found to be abnormally expressed in cancer. IncRNA TUGI expression decreases in glioma and non-small cell lung cancer. However, it can act as a potential tumor suppressor by inhibiting cell proliferation and promoting apoptosis $(26,27)$. Fan et al. (28) found that TUGl expression decreases in various cancer tissues and cell lines. They observed that TUGI induces apoptosis and promotes cell cycle arrest in breast cancer cells (28). We have observed that TUGI is downregulated in ER-negative breast cancer cells after ponatinib treatment. We can suggest that TUGI can suppress proliferation, cell migration, and invasion.

Li et al. (29) found that the downregulation of UCAI reduces cell proliferation, cell migration, and invasion in esophageal squamous cell carcinoma (ESCC). We observed that UCAI decreased expression, such as ESCC cells, in MDA-MB-23I cell lines. As a result, in breast cancer cells treated with ponatinib, ponatinib can suppress metastasis and proliferation.

The downregulation of MALAT-I by SiRNA was found to inhibit prostate cancer cell growth, invasion, and migration in the G0/ Gl phases and inhibited the castration-resistant prostate cancer cell cycle (30). We observed a decrease in expression levels of Malatl in breast cancer cells treated with ponatinib. We suggest that the downregulation of Malat-I can play a role as a prognostic factor in breast cancer.

Li et al. (3I) found that the expression levels of ZEBI ASI are higher in $\mathrm{HCC}$ tissues than in healthy neighboring tissues. They observed that ZEBI ASI expression increases with HCC metastasis. It was determined that survival time was shortened, and that recurrence rates were higher in patients with HCC who had high ZEBI ASI expression. ZEBI ASI supports the prolifer- 
ation and metastasis of HCC; therefore, they asserted that they played an oncogene role in $\mathrm{HCC}$ (32). According to our results, IncRNA ZEB2NAT has a 2.54-fold decrease in the level of the hormone-sensitive breast cancer cells seen as oncogene.

Sun et al. (33) found that the expression of MEG3 is lower in breast cancer tissues than in adjacent tissues. The heterogeneous expression of MEG3 has been observed to induce proliferation by inducing the $\mathrm{G} 0 / \mathrm{Gl}$ proliferation phase and decreases cells in the $S$ (mitotic) phase under in vitro conditions (33). In our study, MEG3 expression was decreased in ER-positive breast cancer cells. Therefore, we believe that apoptosis may be induced.

NEATI acts as an oncogene and tumor suppressor. While the expression of NEATI increases in most cancer tissues, there is a decrease in leukemia and multiple myeloma expression. Ghaforvi-Fard et al. (34) reported a decrease in NEATI expression in various types of breast cancer, esophageal carcinomas, and gliomas. According to our data, the decrease in the expression of IncRNA NEATI determined as an oncogene was found to be significant. As a result, we think that target therapies can be considered as prognostic markers. In our study, the proliferation of the cells should be checked periodically.

We believe that ponatinib can be used as a candidate biomarker for future treatment of breast cancer. Such studies may be promising for a variety of diseases, allowing new IncRNA-based therapeutic strategies to be developed and the identification of new markers to make a diagnosis.

Ethics Committee Approval: Authors declared that the research was conducted according to the principles of the World Medical Association Declaration of Helsinki "Ethical Principles for Medical Research Involving Human Subjects" (amended in October 2013).

\section{Informed Consent: N/A}

Peer-review: Externally peer-reviewed.

Author contributions: Concept - T.B.O., C..K., S.YS., C.G.; Design - T.B.O., C.K., C.G.; Supervision - T.B.O., C.K., S.Y.S., C.G.; Resource - T.B.O.; Materials - T.B.O., C.K.; Data Collection and/or Processing - T.B.O., C..K., S.Y.S., C.G.; Analysis and/or Interpretation - T.B.O., C.K., C.G.; Literature Search -T.B.O., C.K., S.Y.S., C.G.; Writing - T.B.O., C..K.; Critical Reviews - T.B.O., C..K., S.Y.S., C.G.

Conflict of Interest: The authors have no conflicts of interest to declare.

Financial Disclosure: The authors declared that this study has received no financial support.

\section{REFERENCES}

I. Kilic N, Aras S, Cansaran-Duman D. Determination of Vulpinic Acid Effect on Apoptosis and mRNA Expression Levels in Breast Cancer Cell Lines. Anticancer Agents Med Chem 2018; 18: 2032-4I. [CrossRef]

2. Kiliç N, Islakoglu YO, Buyuk I, Gur-Dedeoglu B, Cansaran-Duman D. Determination of Usnic Acid Responsive miRNAs in Breast Cancer Cell Lines. Anticancer Agents Med Chem 2018. doi: 10.2174/I8715206 |866618|||2|20142 [Epub ahead of print]. [CrossRef]

3. Miller GD, Bruno BJ, Lim CS. Resistant mutations in $\mathrm{CML}$ and $\mathrm{Ph}(+)$ ALL - role of ponatinib. Biologics 2014; 8: 243-54. [CrossRef]

4. Gozgit JM, Wong MJ, Moran L, Wardwell S, Mohemmad QK, Narasimhan NI, et al. Ponatinib (AP24534), a multitargeted panFGFR in- hibitor with activity in multiple FGFR-amplified or mutated cancer models. Mol Cancer Ther 2012; II: 690-9. [CrossRef]

5. Baver K, Berger D, Zielinski CC, Valent P, Grunt TW. Hitting two oncogenic machineries in cancer cells: cooperative effects of the multi-kinase inhibitor ponatinib and the BET bromodomain blockers JQI or dBETI on human carcinoma cells. Oncotarget 2018; 9 : 2649I-506. [CrossRef]

6. Guttman M, Amit I, Garber M, French C, Lin MF, Feldser D, et al. Chromatin signature reveals over a thousand highly conserved large non-coding RNAs in mammals. Nature 2009; 458: 223-7. [CrossRef]

7. Kung JT, Colognori D, Lee JT. Long noncoding RNAs: past, present, and future. Genetics 2013; 193: 651-69. [CrossRef]

8. Li J, Liu R, Tang S, Feng F, Wang X, Qi L et al. The effect of long noncoding RNAs HOX transcriptantisense intergenic RNA single-nucleotidepolymorphisms on breast cancer, cervical cancer, andovarian cancer susceptibility: A meta-analysis. J Cell Biochem 2018. doi: 10.1002/jcb.27975. [Epub ahead of print]. [CrossRef]

9. Su JC, Hu XF. Long non-coding RNA HOXAll-AS promotes cell proliferation and metastasis in human breast cancer. Mol Med Rep 2017; 16: 4887-94. [CrossRef]

10. Russo F, Fiscon G, Conte F, Rizzo M, Paci P, Pellegrini M. Interplay Between Long Noncoding RNAs and MicroRNAs in Cancer. Methods Mol Biol 2018; 1819: 75-92. [CrossRef]

II. Liu H, Li J, Koirala P, Ding X, Chen B, Wang Y, et al. Long non-coding RNAs as prognostic markers in human breast cancer. Oncotarget 2016; 7: 20584-96. [CrossRef]

12. Soudyab M, Iranpour M, Ghafouri-Fard S. The Role of Long Non-Coding RNAs in Breast Cancer. Arch Iran Med 2016; 19: 508-17.

13. Sun $H$, Wang $G$, Peng $Y$, Zeng $Y$, Zhu QN, Li TL, et al. HI9 IncRNA mediates $17 \beta$-estradiol-induced cell proliferation in MCF-7 breast cancer cells. Oncol Rep 2015; 33: 3045-52. [CrossRef]

14. Raveh E, Matouk IJ, Gilon M, Hochberg A. The HI9 Long non-coding RNA in cancer initiation, progression and metastasis - a proposed unifying theory. Mol Cancer 2015; 14: I84. [CrossRef]

15. Yoshimura H, Matsuda Y, Yamamoto M, Michishita M, Takahashi K, Sasaki N, et al. Reduced expression of the HI9 long non-coding RNA inhibits pancreatic cancer metastasis. Lab Invest 2018; 98: 814-24. [CrossRef]

16. Chen Q, Sun T, Wang F, Gong B, Xie W, Ma M, et al. Long noncoding RNA IGF2AS is acting as an epigenetic tumor suppressor in human prostate cancer. Urology 2019; 124: el-310. [CrossRef]

17. Wang $Y, H \cup Y, W u G$, Yang $Y$, Tang $Y$, Zhang W, et al. Long noncoding RNA PCAT-I4 induces proliferation and invasion by hepatocellular carcinoma cells by inducing methylation of miR-372. Oncotarget 2017; 8: 34429-4l. [CrossRef]

18. Qiao L, Liu X, Tang Y, Zhao Z, Zhang J, Feng Y. Down regulation of the long non-coding RNA PCAT-I induced growth arrest and apoptosis of colorectal cancer cells. Life Sci 20I7; I88: 37-44. [CrossRef]

19. Iranpour M, Soudyab M, Geranpayeh L, Mirfakhraie R, Azargashb E, Movafagh A, et al. Expression analysis of four long noncoding RNAs in breast cancer. Tumour Biol 2016; 37: 2933-40. [CrossRef]

20. Farhangian P, Jahandoost S, Mowla SJ, Khalili M. Differential expression of long non-coding RNA SOX2OT in gastric adenocarcinoma. Cancer Biomark 20I8; 23: 221-5. [CrossRef]

21. Singh R, Gupta SC, Peng WX, Zhou N, Pochampally R, Atfi A, el al. Regulation of alternative splicing of $\mathrm{Bcl}-\mathrm{x}$ by $\mathrm{BC} 200$ contributes to breast cancer pathogenesis. Cell Death Dis 2016; 7: e2262. [CrossRef]

22. Wu DI, Wang $T$, Ren $C$, Liu L, Kong D, Jin $X$, et al. Downregulation of BC200 in ovarian cancer contributes to cancer cell proliferation and chemoresistance to carboplatin. Oncol Lett 2016; II: II89-94. [CrossRef]

23. Li Y, Zhang $D, Y \cup K, H \cup Y, W \cup Q$, Qian F, et al. CMPDI inhibited human gastric cancer cell proliferation by inducing apoptosis and $G 2 / M$ cell cycle arrest. Biol Res 2018; 5I: II. [CrossRef]

24. Fang $C, H e W, X \cup T$, Dai J, Xu L, Sun F. Upregulation of IncRNA DGCR5 correlates with better prognosis and inhibits bladder cancer progression via transcriptionally facilitating P2I expression. J Cell Physiol 2019; 234: 6254-62. [CrossRef] 
25. Zou H, Wu LX, Yang Y, Li S, Mei Y, Liu YB, et al. IncRNAs PVTI and HARIA are prognosis biomarkers and indicate therapy outcome for diffuse glioma patients. Oncotarget 2017; 8: 78767-80. [CrossRef]

26. J Li, M Zhang, G An, Q Ma. LncRNA TUGI acts as a tumor suppressor in human glioma by promoting cell apoptosis. Exp Biol Med 2016; 24I: 644-9. [CrossRef]

27. Zhang EB, Yin DD, Sun M, Kong R, Liu XH, You LH, et al. P53-regulated long non-coding RNA TUGI affects cell proliferation in human non-small cell lung cancer, partly through epigenetically regulating HOXB7 expression. Cell Death Dis 2014; 5: el243. [CrossRef]

28. Fan S, Yang Z, Ke Z, Huang K, Liu N, Fang X, et al. Downregulation of the long non-coding RNA TUGl is associated with cell proliferation, migration, and invasion in breast cancer. Biomed Pharmacother 2017; 95: 1636-43. [CrossRef]

29. Li JY, Ma X, Zhang CB. Overexpression of long non-coding RNA UCAl predicts a poor prognosis in patients with esophageal squamous cell carcinoma. Int J Clin Exp Pathol 2014; 7: 7938-44.
30. Ren $S$, Liu $Y, X \cup W$, Sun $Y$, Lu J, Wang F, et al. Long noncoding RNA MALAT-I is a new potential therapeutic target for castration resistant prostate cancer. J Urol 2013; 190: 2278-87. [CrossRef]

31. Li T, Xie J, Shen C, Cheng D, Shi Y, Wu Z, et al. Upregulation of long noncoding RNA ZEBI-ASI promotes tumor metastasis and predicts poor prognosis in hepatocellular carcinoma. Oncogene 2016; 35 : 1575-84. [CrossRef]

32. Lan T, Chang L, Wu L, Yuan Y. Downregulation of ZEB2-ASI decreased tumor growth and metastasis in hepatocellular carcinoma. Mol Med Rep 2016; 14: 4606-12. [CrossRef]

33. Sun L, Li Y, Yang B. Downregulated long non-coding RNA MEG3 in breast cancer regulates proliferation, migration and invasion by depending on p53's transcriptional activity. Biochem Biophys Res Commun 2016; 478: 323-9. [CrossRef]

34. Ghaforui-Fard S, Taheri M. Nuclear Enriched Abundant Transcript I (NEATI): A long non-coding RNAwith diverse functions in tumorigenesis. Biomed Pharmacother 2018; III: 5I-9. [CrossRef] 